\title{
Harm-focused policing
}

\author{
Laura Huey*
}

Anyone who knows me will tell you that I am absolutely among the worst of conference attendees. I believe this is an occupational hazard: University Professors are frequently drawn from the ranks of those who like to talk ${ }^{a}$ and who can usually only sustain interest when confronted with highly appealing new ideas or seriously engaging material. I am no exception, and this is why I am frequently found haunting the hallways of hotels and convention centres, waiting for someone interesting to also make a precipitous exit. In many instances, my flights to the corridors reap unexpected rewards. This was the case in August 2015, when, instead of watching PowerPoint slides flicker across a screen, I wandered over to a table sponsored by the Police Foundation and started rifling through their printed materials. Among the pieces I subsequently stashed in my purse to cart home, was a research bulletin written by the criminologist Jerry Ratcliffe (2015) with the title, 'Harm focused policing.'

\section{WHAT IS HARM-FOCUSED POLICING?}

I would define harm-focused policing as a method for identifying places that, and/or offenders who produce the greatest 'harms' within a community and allocating police resources accordingly. This method can be contrasted to policing approaches in which attention is focused on crime counts.

In essence, what harm-focused policing offers is an alternate way to inform police practices and evaluate police performance. Historically, police agencies have been evaluated on their performance in reducing crime as measured by the overall volume of criminal incidents reported to the police. Police were seen as performing well, if, for example, either the overall volume of crime was reduced, or if there were reductions in certain areas (e.g., property crimes).

Researchers have long pointed out the problems associated with crime statistics. Key among these is the fact that official statistics rely on victims or witnesses reporting offences to the police. Yet, for many reasons, a significant number of victims do not report. This results in what academics have called the dark figure of crime'. In relation to relying on crime statistics to inform how police do their work and how they should be evaluated, researchers have also noted two further problems with relying on traditional crime counts:

1. Some crime counts treat all offenses equally (e.g., mischief and sexual assault are both crimes)
2. Other counts distinguish by type (violent versus property offenses), but treat all offenses within a category as equal (i.e., both assault and first-degree murder are violent crimes).

Either way, we fail to take into account that: "All crimes are not created equal. Counting them as if they are fosters distortion of risk assessments, resource allocation, and accountability" (Sherman, Neyroud \& Neyroud, 2016, p. 1). To address these issues, researchers have begun using different conceptions of 'harm' and how to measure 'crime as harm' to develop tools to help police more efficiently allocate resources and to select the most effective crime reduction strategies.

\section{HARM INDICES}

Much of the research in this area has centred on the creation of 'harm indices'. The harm index approach typically involves researchers assigning a 'weight' to each type of crime based on a measure of the perceived severity or gravity of the offence. To illustrate, first-degree murder would likely be weighted more heavily than manslaughter, as it is socially and legally viewed as more 'harmful'. In this section, I want to look at two harm indices: the Canadian Crime Severity Index and the Cambridge Harm Index.

\section{Canadian Crime Severity Index}

Seven years ago, Statistics Canada (2009) was among the first to employ the concept of a 'harm index', when they introduced the Canadian Crime Severity Index (CCSI). The purpose of the CCSI is to answer two sets of questions:

a. Is the current volume of reported crime more or less serious than in previous years?

b. Is police-reported crime in a particular city or province more or less serious than in other cities or provinces? Or in Canada overall?

As with later 'harm' measuring systems, the Canadian Crime Severity Index (CCSI) uses a 'weighting' system in which each type of criminal offense is given a weight to

\footnotetext{
a In support of this contention I point out that, when Professors do sit through talks, it appears that many do so with barely concealed impatience, waiting for the Q\&A session when they will spring up with a 20-minute comment disguised as a question.
} 
correspond to its relative seriousness. The 'weights' are based on two factors:

1. The incarceration rate for this offense - that is, the proportion of offenders who receive a sentence of incarceration; and

2. The average length (in days) of a prison sentence for this offense.

In other words, the weighting is based on the sentences offenders typically receive from the courts. To calculate 'harm', the overall annual number of crimes committed for a particular offense (as reported to police) are multiplied by the weight assigned. These figures can then be added together and divided by the population total to calculate overall 'harm.' To ensure that the weighting reflects social, legal and other changes affecting sentencing, the CCSI weights are to be updated every five years.

\section{Cambridge Crime Harm Index}

The Cambridge Crime Harm Index (CCHI) was developed by Larry Sherman and colleagues (2016) from the University of Cambridge. Like the CCSI, the Cambridge version also uses a weighting system based on offender sentences. Where the two differ is that the CCHI weights are derived from UK sentencing guidelines and the median length (in days) that a first-time offender would receive for a particular offense. Similar to the CCSI, this 'weight' is then multiplied by the number of recorded events for each offense type for a total 'cost' of that crime to the community.

Why use sentencing guidelines for a first-time offender? What about those individuals who commit multiple offenses? The CCHI creators argue that that the cost or 'harm' of a crime to the victims and/or their families does not change based on whether someone is a multiple offender:

"Whether a first time offender or a serial killer murders someone, the murder creates the same harm to the victims, his or her families, and communities. The actual punishment each offender 'deserves' to receive is a very different question from how much harm the crime has caused. It is that concept of harm, independent of culpability, which we aim to measure in the Cambridge CHI." (Sherman, Neyroud \& Neyroud, 2016, p. 2).

\section{HOW CAN THESE CONCEPTS BE USED IN POLICING? HOW HAVE THEY BEEN USED IN POLICING?}

Proponents of harm-focused policing argue that, by moving away from crime counts towards measuring the impact of crime (however 'harm' is calculated), we can get an improved picture of the problems facing our communities and how best to allocate resources. Sherman (2011), for example, has stated that a harm index approach can be more costeffective than traditional police resource allocation strategies because it allows agencies to rebalance priorities away from reducing crime counts across multiple offence categories to a much narrower focus on those crimes, areas, and offenders which produce the most harm in a community (see also Ratcliffe, 2015).
These ideas are currently being put to the test in a number of studies conducted with police agencies throughout the U.K. For example, the Leicestershire Police are using the CCHI to identify 'harm spots' and 'most harmful offenders.' Armed with this information, they are targeting both harmful places and offenders through a reallocation of resources, changing patrol patterns and reworking their offender management strategies. The CCHI has also been used by Suffolk Constabulary to identify those domestic violence offenders, among some 32,000 calls for service, who generate the greatest harm - Sherman's 'power few' (2007) — and therefore require most intensive interventions.

The potential usefulness of harm-focused policing for addressing crime and disorder was also recently tested in a study by the criminologist Jerry Ratcliffe (2014, 2015). Focusing on two police districts in the city of Philadelphia, Ratcliffe applied a weighting scheme similar to the $\mathrm{CCHI}$ to the volume of reported criminal offences within these areas to generate a map of 'harmful places' or 'harm hot spots.' Where Ratcliffe's work differed significantly is that he drew on a broader definition of 'harm' that included traffic accidents, which were also weighted. He also drew on data beyond crime statistics, including 'stop and frisk' data. Extending beyond 'harm hot spots,' Ratcliffe's work, like that of Sherman et al. (2016) suggests that similar metrics can be used to show the harm produced by individual offenders.

\section{SOME THOUGHTS}

Will harm-focused policing catch on in across Canada and change how policing is performed and evaluated here? Hard to say. My track record at prediction is on par with my track record as a conference-goer — 'a bit' spotty — so I wouldn't place bets either way. What I will say is this: given that Canadian policing is currently going through a period of what our U.K. colleagues have termed 'austerity policing,' any strategies that hold the potential to maximize efficiency and effectiveness in dealing with crime and community safety issues are worth putting to the test. ${ }^{b}$ Particularly worthwhile, I would argue, are those strategies explicitly focused on the identification and targeting of the harmful impacts of the 'power few' - those individuals and groups that generate disproportionate levels of harm within communities.

There is, of course, an additional potential benefit to police agencies of considering harm-focused approaches, and it is a benefit that some canny organizations have already begun to recognize. Police agencies have historically tied their fortunes to the vagaries of crime stats. This has proven to be something of a dysfunctional relationship as we have seen over the past few years in the U.K, where falling crime stats launched a new discourse - 'why do we need so many police officers?' - and rounds of resulting cuts to services. In vain, police representatives there pointed out that policing is so much more than fighting crime and that crime statistics thus offer only a partial view into the daily demands of policing.

\footnotetext{
b To be clear: by 'putting to the test' I mean carefully implementing pilot projects, which are then subjected to rigorous, independent evaluation and, if adopted, continuous tracking over time. The days of copying programs and implementing them wholesale without careful evaluation are, or should be, over.
} 
How does harm-focused policing potentially alter this discourse? As a rather canny colleague from the policing community observed, it doesn't hurt for police agencies to have independently evaluated tools that not only increase efficiencies, but allow police to more effectively explain to communities how and why police resources are allocated. As he noted, 'harm' makes for a more relatable, indeed, compelling story. Indeed.

\section{CONFLICT OF INTEREST DISCLOSURES}

The author declares that they have no conflicts of interest.

\section{AUTHOR AFFILIATIONS}

*Department of Sociology, University of Western Ontario, and Canadian Society of Evidence Based Policing, University of Western Ontario, London, ON, Canada.

REFERENCES

Ratcliffe, J. (2014). Towards an index for harm-focused policing. Policing, 9(2), 164-182.
Ratcliffe, J. (2015). Harm-focused policing. Ideas in American Policing, 19. Police Foundation research bulletin. Available at: https://www. policefoundation.org/the-police-foundation-releases-harm-focused policing-the-latest-in-the-foundations-ideas-in-american-policing-series

Sherman, L. (2007). The power few hypothesis: experimental criminology and the reduction of harm. Journal of Experimental Criminology, 3(2) 299-321.

Sherman, L. (2011). Al Capone, the sword of Damocles, and the policecorrections budget ratio. Criminology and Public Policy, 10(1), 195-206.

Sherman, L., Neyroud, P., \& Neyroud, E. (2016). The Cambridge Crime Harm Index: measuring total harm from crime based on sentencing guidelines [Advance access copy]. Policing, 10, 1093. Available at: http://policing. oxfordjournals.org/content/early/2016/03/09/police.paw003

Statistics Canada. (2009). Measuring crime in Canada: introducing the Crime Severity Index and improvements to the Uniform Crime Reporting Survey. Catalogue No. 85-004-x. Ottawa: Statistics Canada. Available at: http://www.statcan.gc.ca/pub/85-004-x/85-004-x2009001-eng.htm 